\title{
Efeitos do saber-fazer de psicólogos na Saúde Mental do Piauí
}

\author{
João Paulo Macedo, ${ }^{I, \star M a g d a ~ D i m e n s t e i n ~}{ }^{I I}$ \\ ${ }^{I}$ Universidade Federal do Piauí, Teresina, PI, Brasil \\ ${ }^{\text {II } U n i v e r s i d a d e ~ F e d e r a l ~ d o ~ R i o ~ G r a n d e ~ d o ~ N o r t e, ~ N a t a l, ~ R N, ~ B r a s i l ~}$
}

\begin{abstract}
Resumo
Pretende-se analisar os saberes e práticas de psicólogos que atuam na rede de Saúde Mental, bem como seus efeitos na produção do cuidado e modos de implicação destes profissionais com o processo de Reforma Psiquiátrica em curso no país. Trata-se de um estudo qualitativo, com uso de entrevista semiestruturada $(n=29)$ e observação dos processos de trabalho e organização dos serviços localizados em Teresina-PI: CAPS, Unidades Básicas de Saúde, serviços ambulatoriais, hospitais psiquiátricos e gerência de Saúde Mental. Os resultados indicam que a formação graduada e pós-graduada aporta poucos conhecimentos teóricos e práticos para os psicólogos atuarem na Saúde Mental. Os norteadores teórico-técnicos e prático-profissionais escolhidos pelos entrevistados indicam um compromisso com o saber-fazer clássico do psicólogo, pouco consoante com a perspectiva da Atenção Psicossocial, e consequentemente, com a sustentação política do processo de Reforma Psiquiátrica e Luta Antimanicomial.
\end{abstract}

Palavras-chave: formação do psicólogo; reforma psiquiátrica; abordagem psicossocial.

\section{Effects of psychologist's know-how in mental health in Piauí}

\begin{abstract}
The objective is to analyze the knowledge and the practices of psychologists acting in Mental Health, as well as its effects on the care production and in the ways as those professionals are implicated on the Psychiatric Reform process undergoing in the country. It is a qualitative study, using semi-structured interview $(n=29)$ and observing the work processes and services organization: CAPS, primary health unities and outpatient services, psychiatric hospitals and mental health management. Results indicated that undergraduate and postgraduate formation favored little support for Piaui psychologists to act in Mental Health. The theoreticaltechnical and practical-professional guiding chosen by the respondents qualify them as well committed professional with the classic know-how of what defines the psychologist nature of work; on the other hand, they place us little consonant with the psychosocial care perspective, consequently, with political sustentation for the process of psychiatric reform underway in the country.
\end{abstract}

Keywords: psychologist formation; psychiatric reform; psychosocial approach.

\section{Introdução}

O presente estudo analisa os saberes e práticas dos psicólogos que atuam na Política de Saúde Mental do Piauí, bem como seus efeitos na produção do cuidado e na maneira como tais profissionais se implicam com o processo de Reforma Psiquiátrica em curso no país. Para chegarmos ao objetivo proposto, partimos do tensionamento entre duas questões, muito atuais, que têm demarcado a inserção dos psicólogos na Política de Saúde Mental. De um lado, observa-se que a ampliação da rede substitutiva (Centros de Atenção Psicossocial [CAPS], Núcleos de Apoio à Saúde da Família [NASF], Serviços Residenciais Terapêuticos [SRT], Consultórios de Rua, Casas de Acolhimento Transitório [CTA], Serviços de Atenção de Urgência e Emergência [SAMU e UPA24h] e Atenção Hospitalar, além das Estratégias de Desinstitucionalização e Reabilitação Psicossocial) expressa um importante e complexo dispositivo de expansão e interiorização dos psicólogos em todo o território brasileiro. Do outro lado, apesar dos avanços quanto à ampliação e reversão da rede asilar para a psicossocial, falta aos profissionais, em geral, maior embasamento para a sustentação da Estratégia de Atenção Psicossocial, criação de novas perspectivas de cuidado e efetivação do trabalho em rede.

\footnotetext{
^Endereço para correspondência: Universidade Federal do Piauí, Campus Ministro Reis Velloso, Departamento de Psicologia. Av. São Sebastião, 2819 - Reis Veloso. CEP: 64202020 - Parnaíba, PI - Brasil.E-mail: jpmacedo@ufpi.edu. br,magda@ufrnet.br
}

O principal efeito quanto à falta de embasamento ou de norteadores teórico-práticos para atuar na Política de Saúde Mental, conforme apontam inúmeros autores (RIBEIRO; LUZIO, 2008; BOARINI; BORGES, 2009; FERREIRA NETO, 2008; SALES; DIMENSTEIN, 2009a, 2009b; MACEDO; DIMENSTEIN, 2011; dentre outros), é a filiação das práticas profissionais ao paradigma asilar e o pouco diálogo ou vínculo dos trabalhadores com o modo psicossocial de atenção. Para Yasui e Costa-Rosa (2008), o paradigma asilar ancora-se no entendimento de que a loucura é uma doença, portanto, pressupõe um processo doença-cura em que os determinantes orgânicos são seu principal agente causador. Além disso, os processos de trabalho envolvidos estão centrados na supressão do sintoma, através da hospitalização e da medicalização, portanto, na objetificação do paciente, cujos saberes envolvidos encontram-se hierarquizados pelo protagonismo médico. Diferente deste, o modo psicossocial considera os fatores políticos, culturais, biopsicossociais e territoriais como determinantes do sofrimento psíquico, apostando nos meios básicos enquanto dispositivos de reintegração social, além dos conhecidos procedimentos psicoterápicos e farmacoterápico. Portanto, investe-se na desinstitucionalização dos valores, verdades e práticas asilares, bem como na construção de redes sociais de cuidado e experimentação de novas possibilidades de vida e sociabilidades que escapem à produção em série vista nos manicômios. Por fim, a ênfase da ação do cuidado está não no profissional médico, mas no protagonismo 
e empoderamento dos usuários e da comunidade na efetivação do cuidado e participação social nos processos decisórios, associado às ações de produção de cidadania.

Apesar da clara diferença entre os dois modelos e da orientação da Política Nacional de Saúde Mental para a perspectiva da desinstitucionalização e do paradigma psicossocial, os trabalhadores que atuam neste campo têm encontrado grandes desafios no modo de empreender tal perspectiva no cotidiano de suas práticas. Mesmo com as conquistas recentes, há uma necessidade clara de estruturação de uma rede psicossocial que esteja integrada e articulada, inclusive intersetorialmente com outras políticas públicas. As demandas que têm surgido no setor são prova disso: o crack e a internação compulsória de dependentes químicos; adolescentes (usuários de drogas) em conflito com a lei; atenção à crise e urgência psiquiátrica; pacientes crônicos; população de rua; assistência ao público infantil (autismo e medicalização do sujeito escolar); suporte familiar; violência social e catástrofes/desastres; casos de transtornos psiquiátricos menores (VASCONCELOS, 2010).

No entanto, ao lado da necessidade de fortalecimento e apoio institucional dos serviços, bem como da sociedade civil para respondermos aos desafios da Política de Saúde Mental, há um aspecto anterior que não pode ser esquecido: a sustentação técnica e organizativa de trabalhadores e gestores para a efetivação da proposta da Estratégia de Atenção Psicossocial, sob o foco da desinstitucionalização. Somente a partir desta sustentação é que, talvez, possamos oferecer serviços de qualidade e implicados com a produção do cuidado, com a reconstrução da vida e a cidadania de usuários e familiares. Além disso, são práticas que também precisam gerar sustentação política para avançarmos no fortalecimento sociocultural do movimento de Reforma, portanto, na construção de um novo lugar social para a loucura na sociedade.

Neste caso, compreendemos que, para além de realizar estudos que apenas identifiquem os saberes e as práticas dos profissionais que atuam na Política de Saúde Mental, precisamos avançar com pesquisas em que as análises possam evidenciar e discutir os efeitos que tais operações acarretam na produção do cuidado e na maneira como tais profissionais se implicam no processo de Reforma Psiquiátrica em curso no país. Deste modo, apresentamos a pergunta de partida que provocou a realização deste estudo: os psicólogos têm articulado em suas práticas profissionais atuações que conjugam ação técnica e ação política?

Circunscrevemos tais reflexões aos psicólogos piauienses, em função de algumas particularidades locais, a exemplo do processo tardio de implantação dos serviços extra-hospitalares e de base territorial em todo o estado. Entendemos que o contexto piauiense, semelhante a outras realidades do país, concentra alguns acontecimentos que sinaliza bem o momento atual de tentativa de consolidação da Política de Saúde Mental. Trata-se de um processo recente, iniciado em 2004, quando foram implantados seus primeiros serviços substitutivos
(ROSA, 2006). Apesar de tardio, rapidamente houve a expansão dos mesmos, de modo que atualmente temos a quinta melhor cobertura populacional (91\%) em saúde mental do país (BRASIL, 2011), muito embora registre muitas dificuldades.

Por outro lado, também assistimos a implantação tardia dos primeiros cursos de psicologia no Piaú, que ocorreu a partir de 1998, e rapidamente se expandiu, totalizando seis cursos. Esse quadro de rápido crescimento do número de cursos de psicologia, bem como do número de profissionais, não é restrito apenas a realidade piauiense. O próprio processo de expansão das políticas públicas no Brasil, especialmente na Saúde e Assistência social, é contemporâneo ao crescimento da profissão em todo o país. Tal fato tem caracterizado o setor público como o maior empregador (40,3\%) dos psicólogos no Brasil (MACÊDO; HELOANI; CASSIOLATO, 2010), tendo a realidade piauiense um percentual ainda maior $(43,4 \%)$ de profissionais institucionalizados na seguridade social, com destaque para saúde e assistência social.

Desse modo, é urgente problematizarmos a atuação e formação do psicólogo nesses campos, especialmente relacionado à Saúde Mental, considerando a ampliação do mercado profissional nessa área e os desafios anteriormente referidos. Nessas circunstâncias, tratar dos efeitos do saber-fazer dos psicólogos piauienses na Política de Saúde Mental não se refere apenas a uma questão ou reflexão local, mas expressa uma problemática nacional. Pretendemos, portanto, avançar nas análises aqui propostas, dialogando-as com os diversos estudos que têm tratado sobre o tema da formação e atuação do psicólogo brasileiro. Assim, buscaremos cumprir dois objetivos específicos: de um lado, identificar os saberes e as práticas que embasam as compreensões e as estratégias de ação dos psicólogos piauienses na Política de Saúde Mental; do outro, analisar os efeitos que tais "escolhas" teóricas e práticas implicam sobre o modo como esses mesmos profissionais se posicionam, comparecem e participam do processo de Reforma Psiquiátrica em curso no país.

\section{Proposta Metodológica}

Trata-se de um estudo exploratório de natureza qualitativa, tendo como participantes psicólogos que atuam na rede de saúde mental da capital do Piauí. Em Teresina, contatamos na época da realização do estudo com o total de 82 psicólogos atuando na rede pública de saúde. Destes, 44 profissionais atuavam em 17 serviços da rede de saúde mental da capital, que compõem os três níveis de complexidade do SUS. Por questão de agenda, entrevistamos 29 psicólogos que atuavam em 07 Centros/Unidades Básicas de Saúde $(\mathrm{n}=7)$, em quatro Centros de Atenção Psicossocial/CAPS ( $\mathrm{n}=13)$, nos dois Hospitais Psiquiátricos ${ }^{1}(\mathrm{n}=7)$ e na Gerência Estadual de Saúde Mental $(\mathrm{n}=2)$.

\footnotetext{
${ }^{1}$ Em 2010, a rede psicossocial do Piauí passou a contar com somente um hospital psiquiátrico; o outro encerrou sua atividade por interesse dos proprietários, pondo a venda o valorizado terreno que o hospital possuía para uma rede de shopping centers.
}

Fractal, Rev. Psicol., v. 28 - n. 1, p. 37-45, 2016 
Como instrumentos de coleta de dados, utilizou-se entrevista semiestruturada e observação dos processos de trabalho e organização dos serviços. A entrevista abordou aspectos da formação graduada e pós-graduada; ferramentas teóricas e metodológicas; atividades desenvolvidas; organização dos processos de trabalho e dificuldades para atuar no setor. Quanto às análises dos dados, trabalhamos com análise de conteúdo baseada em Minayo (2000), tendo como procedimentos: categorização, inferência e interpretação dos dados. Os resultados foram organizados a partir dos seguintes eixos de análise: formação; saberes e práticas; e os efeitos das escolhas teórico-metodológicas e dos modos de atuar dos psicólogos para reforma psiquiátrica.

Para a realização deste estudo, os entrevistados assinaram o TCLE dando consentimento para a realização da pesquisa, além de contarmos com a autorização da Secretaria Estadual de Saúde/SESAPI e Fundação Municipal de Saúde/FMS.

\section{Resultados}

Os psicólogos entrevistados foram em sua maioria mulheres $(79,3 \%)$, jovens $(58,6 \%)$, formados há menos de 10 anos (62\%). Quanto ao vínculo empregatício, são estatutários da FMS ou da SESAPI, por meio de concurso público (45\%); outros conquistaram a estabilidade do cargo $(31 \%)$ por terem ingressado no serviço público antes da Constituição de 1988; e os demais, em torno de $24 \%$ dos entrevistados, são terceirizados. Muitos estão no primeiro emprego, sobretudo os profissionais dos CAPS. Neste caso, percebe-se na ampla maioria dos entrevistados a falta de uma trajetória ou experiência profissional prévia na área.

\section{Formação dos psicólogos que atuam na Política de Saúde Mental do Piauí}

Em relação à formação, observa-se uma diversidade de agências formadoras, locais e períodos em que realizaram seus cursos. Os profissionais dos CAPS $(\mathrm{n}=$ 13), em sua maioria (77\%), concluíram o curso a partir de 2003, são procedentes dos cursos locais, especialmente da Faculdade Santo Agostinho-PI $(\mathrm{n}=6)$, Universidade Estadual do Piauí $(\mathrm{n}=2)$ e Faculdade Integral Diferencial $(\mathrm{n}=1)$. Os demais são oriundos de agências formadoras nos estados do CE, MA, SP e RJ. Quanto aos profissionais que atuam na atenção básica e rede ambulatorial, verificase outra configuração: $71,42 \%$ foram formados na década de 1980 e início dos anos 1990, sendo que o número de psicólogos formados fora do Piauí $(\mathrm{n}=5)$, com destaque para $\mathrm{PB}$ e PE, é maior do que aqueles formados no próprio estado $(n=2)$. Com relação aos profissionais que atuam nos hospitais psiquiátricos, evidencia-se maior número de psicólogos formados fora do Piauí $(\mathrm{n}=6)$, sobressaindose os estados de SP, RJ, PB, PE, CE, tendo ocorrido no final da década de 1970 ou nos anos 80. Deste modo, na medida em que retrocedemos no tempo, diversificam-se os locais e instituições de formação. No geral, a maioria dos entrevistados $(70,37 \%)$ é oriunda de instituições

Fractal, Rev. Psicol., v. 28 - n. 1, p. 37-45, 2016 privadas, realidade completamente condizente com o perfil do psicólogo brasileiro publicado mais recentemente (BASTOS; GONDIM; RODRIGUES, 2010).

Quanto ao percurso de suas graduações na preparação profissional para atuar nos serviços de Saúde Mental, os entrevistados foram unânimes em referir que seus cursos preparam pouco. Tal reclame reforça uma problemática já bastante recorrente nos inúmeros estudos sobre a formação que evidenciam pouco preparo dos psicólogos para ingressarem nas políticas públicas, mesmo considerando as graduações realizadas mais recentemente (CAMPOS; GUARIDO, 2007; DIMENSTEIN, 2009, FERREIRA NETO, 2010; dentre outros). Porém, o que chamou mais atenção nos dados levantados foram as semelhanças entre os entrevistados formados antes e depois de 1998 quanto a preparação para atuar na Saúde Mental.

Quanto aos primeiros $(\mathrm{n}=13)$, todos relataram não ter cursado disciplinas relacionadas com a área ou mesmo de saúde pública e/ou políticas públicas, muito menos ter realizado práticas ou experiências de estágio nesse campo ou em contextos institucionais/comunitário. Ademais, criticaram o caráter predominantemente clínico das formações, com foco somente no plano individual e intrapsicológico, fundamentado única e exclusivamente pelas abordagens tradicionais da clínica psicológica.

Por outro lado, pelo menos cinco dos profissionais (hospital $=3$, ambulatório $=2$ e CAPS $=1$ ) que se formaram antes de 1998 referiram terem participado de experiências extracurriculares por conta própria em hospitais psiquiátricos na época de suas graduações. No entanto, as atividades realizadas por esses profissionais eram basicamente identificar processos psicopatológicos e fortalecer a adesão dos pacientes ao tratamento psicofarmacológico por meio da psicoterapia individual e grupal. Apesar disso, foi o contato com as condições da assistência psiquiátrica oferecida nos serviços que fez com que se vinculassem ideologicamente ao movimento da Reforma Psiquiátrica; muito embora, no plano teórico-técnico, eles reafirmassem, categoricamente, as bases epistemológicas, conceituais e jurídicas definidoras da loucura enquanto doença, portanto, um mal passível de ser tratado e curado.

Nesses termos, o campo de ações técnicas desses profissionais, que ingressaram na Política de Saúde Mental do Piauí anterior ao ano de 1998 , não poderia ser outro senão seu comprometimento com as tradicionais práticas de: a) identificação dos processos psicopatológicos; b) prevenção e o controle dos fatores desencadeadores da crise psiquiátrica; c) busca de estratégias para a remissão dos sintomas; e d) diminuição/monitoramento dos níveis de periculosidade do paciente.

Quanto ao segundo grupo $(\mathrm{n}=16)$, aqueles formados a partir dos anos 2000, especialmente oriundos dos cursos de Teresina $(n=14)$, os relatos não foram tão diferentes em relação ao grupo anterior. Por serem cursos que foram criados no mesmo período em que o debate sobre os modelos de formação do psicólogo brasileiro, e também da discussão e implantação das Novas 
Diretrizes Curriculares no plano nacional ganharam força, esperava-se que as agencias formadoras no Piauí apresentassem outro perfil de formação. Nesse aspecto, todos os 14 entrevistados criticaram fortemente a matriz curricular em que foram graduados. As reclamações centraram-se no fato de que mesmo com os currículos apresentando maior variação de concepções teóricas e técnicas psicológicas, inclusive considerando o debate sobre a atuação em espaços institucionais e comunitários, com práticas voltadas para as ações preventivas e de promoção de saúde (qualidade de vida), ainda assim, sobressaiu, com grande ênfase, disciplinas voltadas para a manutenção do foco na identificação dos aspectos psicológicos (diagnóstico) e intervenções voltadas para a resolução de problemas de ajustamento em termos comportamentais e afetivos, e/ou de personalidade.

Não obstante, identificamos na realidade atual questões semelhantes àquelas problematizadas por Dimenstein (1998, 2000 e 2001) em seus estudos sobre o contexto teresinense há quase 20 anos. Ou seja, ao longo desse período os cursos de psicologia piauienses demonstraram pouca inclinação quanto à incorporação de uma "nova concepção de prática profissional" associada à produção do cuidado, de direitos, da cidadania e do processo de "construção de sujeitos (e subjetividades) com capacidade de ação e de proposição" para a efetivação da proposta da desinstitucionalização e da atenção psicossocial (DIMENSTEIN, 2001, p. 62).

Por outro lado, dentre os 14 profissionais formados mais recentemente, seis deles (egressos da UESPI e UFMA) referiram que suas graduações garantiram disciplinas voltadas para a área da saúde, com discussões em torno da saúde pública e da reforma sanitária e psiquiátrica. No entanto, os mesmos ressaltaram que no âmbito prático e nas experiências de estágios, não tiveram qualquer subsídio teórico-técnico para desenvolver ações que expressassem o entendimento da saúde como um campo multideterminado e pautado pela cultura interprofissional e interdisciplinar, inclusive desenvolvendo experiências inter e multiprofissionais, que valorizassem o trabalho em equipe e ações de cuidado na perspectiva psicossocial e da saúde coletiva (OLIVEIRA, 2008). Com isso, compreendemos que não muito diferente dos outros (formandos antes de 1998), os entrevistados tiveram formações que valorizaram somente o fazer técnico clássico da psicologia, ou quando muito, práticas preventivistas vinculadas a "estratégia de patologização e normalização social com a inscrição do sofrimento psíquico e do mal-estar social no rol das patologias", portanto, do binômio doença-cura (AMARANTE, 1996, p. 17).

Em resumo, observou-se que as graduações daqueles que concluíram o curso antes e depois de 1998 revelaram muita proximidade quanto aos saberes e experiências práticas desenvolvidos em suas formações. Daí a importância de pensar uma política de formação efetiva que supere tais imprecisões, pois entendemos que tal realidade não é localizada, ou seja, exclusiva da formação dos psicólogos piauienses, especialmente se considerarmos os inúmeros estudos existentes sobre o tema que problematizam sobre o pouco preparo dos psicólogos brasileiros para ingressarem na saúde pública, consequentemente na Política de Saúde Mental.

\section{Os saberes e as práticas operados pelos psicólogos que atuam na Saúde Mental do Piauí}

As perspectivas teóricas mais presentes entre os psicólogos que atuam na Política de Saúde Mental na capital piauiense são as abordagens clínicas (83\%). Os relatos destacaram as de base humanista e fenomenológica (45\%), psicanalistas (28\%), cognitivas e comportamentais $(18 \%)$ e corporais (4\%). Se estratificarmos esse dado por serviços todos os psicólogos que atuam nos CAPS, assim como a maioria que atua na atenção básica e ambulatórios (71\%), ou mesmo no hospital psiquiátrico (71\%), referiram fundamentar suas ações preferencialmente com base nisso. Tais saberes centram-se, notadamente, em estudos psicopatológicos e clínicos de casos individuais, com realização de diagnóstico visando remissão de sintomas, estabilidade emocional e afetiva do paciente e reestruturação psíquica. Somente uma minoria dos entrevistados $(17 \%)$ referiu fundamentar seu trabalho na atenção psicossocial e saúde coletiva, com foco na reforma e na desinstitucionalização psiquiátrica.

Quanto ao campo das práticas profissionais, os entrevistados que atuam nos CAPS referiram participar e desenvolver ações de triagem, a qual denominam como acolhimento; atendimento individual (ambulatório interno), com base no modelo psicoterápico breve/focal; trabalhos com grupos de usuários e familiares, tanto sob a perspectiva informativa e educativa, quanto terapêtica, definidos por diagnóstico, para fortalecer a adesão ao tratamento medicamentoso ou ainda para esclarecer os direitos dos usuários e familiares. Outras atividades também são realizadas com menor participação dos entrevistados, dentro e fora dos CAPS, no objetivo de envolver usuários e familiares na socialização e treinamento de habilidades sociais: oficinas terapêuticas, oficinas de atividades laborais, atividades físicas/torneio esportivo, atividades recreativas, passeios/caminhadas, confraternizações e atividades de comemoração da luta antimanicomial (estas últimas dentro dos serviços).

$\mathrm{Na}$ atenção básica e setor ambulatorial, os entrevistados desenvolvem basicamente o atendimento individual, com base no modelo psicoterápico, sendo raro o trabalho em equipe multiprofissional e interdisciplinar. Além disso, referiram não desenvolver: a) atividades em grupo por falta de espaço adequado; b) ações de planejamento ou promoção em saúde, em função da incompatibilidade de horário com outros técnicos; c) ações de suporte ou integradas à Estratégia Saúde da Família, em função da agenda de atendimento; e d) ações voltadas para o território e população adstrita de cada unidade, por entender que não é de sua competência realizar tal atividade. Considerando a pouca ênfase de ações de saúde mental na atenção básica, os entrevistados referiram ser raro o atendimento de pacientes psiquiátricos, especialmente oriundos de 
CAPS ou hospital psiquiátrico; porém, quando surgem, apenas fazem triagem e orientam o paciente a procurar os serviços especializados. Para os casos de transtorno mental leve ou comum, os entrevistados relataram acompanhar o caso, apesar de pouca procura nos serviços.

Quanto aos profissionais dos hospitais psiquiátricos, especialmente no hospital-dia e ambulatório (localizados em um dos hospitais pesquisados), estes referiram desenvolver atendimentos individuais com base no modelo psicoterápico, além de trabalhos com grupos (terapia de grupo e ações educativas). Quanto ao trabalho nas enfermarias, normalmente há atendimento individual para acompanhamento e evolução do quadro clínicopsiquiátrico, além de atividades em grupo para fortalecer a adesão dos pacientes ao tratamento medicamentoso.

Especificamente entre os entrevistados que fundamentam seu trabalho nos aportes da atenção psicossocial e saúde coletiva, destacam-se somente três que atuam nos Centros/Unidades de Saúde e outros dois que atuam nos hospitais psiquiátricos. No entanto, por estarem em serviços com condições físicas insuficientes, carência de recursos humanos qualificados para o trabalho em equipe e falta de ações gerenciais para o trabalho em rede, avançam muito pouco na condução de práticas sob a perspectiva da desinstitucionalização, do protagonismo dos usuários/familiares e do trabalho de continuidade do cuidado pós-alta.

No geral, dois aspectos chamam atenção quanto aos saberes e práticas operados pelos psicólogos entrevistados: independente do local, da época e da IES onde realizaram seus cursos de graduação e do local de atuação, inclusive considerando a presença dos psicólogos nos diferentes níveis de complexidade da rede de Saúde Mental pesquisada (Centros/Unidades de Saúde, CAPS e Hospital Psiquiátrico), quase não há diferenças quanto às formações realizadas, incluindo o rol de saberes e práticas "tradicionais" envolvidas no preparo profissional para atuar nos serviços.

Portanto, observa-se não apenas que a formação dos psicólogos parece ser atemporal, mas que a forma como esses profissionais atuam, as ferramentas teóricas e práticas que priorizam, além dos modos de intervir em que se apoiam, tudo parece ser igual independente do local, da população, das necessidades e da organização dos serviços em que esse profissional está inserido, salvo, é claro, algumas poucas exceções. Percebe-se que a grande maioria dos entrevistados $(n=24)$ maneja campos de saberes bastante homogêneos, fundamentalmente ancorados no campo da psicologia e psiquiatria tradicionais. Ou seja, saberes pautados no princípio doença-cura, com compreensão predominantemente orgânica e/ou intrapsíquica do processo saúde-doença. Além disso, são saberes com ações voltadas para a descrição nosográfica e/ou comportamental do quadro psiquiátrico e elaboração de estratégias terapêuticas centradas, quase que exclusivamente, na reversão sintomatológica a partir da ação medicamentosa e psicoterápica (YASUI; COSTA-ROSA, 2008). Entre os entrevistados, a importância do domínio de conhecimentos em torno de disciplinas como psicopatologia, técnicas diagnósticas e de exame psicológico e psicopatológico, técnicas psicoterápicas, desenvolvimento atípico e manejo clínico (psicoterapia), é visível.

Dessa maneira, nota-se o pouco diálogo com conhecimentos de outras áreas, especialmente com saberes que valorizam a historicidade e a alteridade humana, a exemplo da antropologia; ou que amplie o entendimento dos contextos e do perfil sócio-epidemiológico das clientelas com que trabalham, como por exemplo, a sociologia, a ciência política, a epidemiologia social, a geografia da saúde e a saúde coletiva (BASTOS; ACHCAR, 1994; CAMPOS; GUARIDO, 2007).

A "exceção" ocorre quando é necessário compreender melhor um caso clínico em termos diagnósticos ou alguma questão em torno da esfera familiar ou social. Nestes casos, percebe-se o diálogo dos psicólogos com psiquiatras ou assistentes sociais para elucidar dúvidas; cenário que deixa bastante evidente a manutenção dos campos dos especialismos presentes nos serviços (PASSOS; BARROS, 2000), pois o fundamental é operar conhecimentos que qualifiquem as ações profissionais frente à precisão diagnóstica, extraindo o melhor conhecimento sobre o quadro clínico do paciente, consequentemente realizar escolhas terapêuticas com foco na remissão dos sintomas e minimização do sofrimento psíquico.

Nesse sentido, percebe-se dentre os entrevistados, que enquanto aqueles de formações mais antigas (antes de 1998) atentavam muito pouco para as concepções mais ampliadas de saúde (CAMPOS, 2003), inclusive com poucas possibilidades de atuações para além do modelo médico-psiquiátrico, portanto, guardião do paradigma asilar (OLIVEIRA, 2008); aqueles com formações mais recentes (a partir dos anos 2000), apesar de reconheceram a necessidade do trabalho ancorado pela perspectiva psicossocial, na prática demonstraram muitas dificuldades em operacionalizar tais entendimentos, conceitos e posturas profissionais, no cotidiano dos serviços.

Para Oliveira (2008), tais aspectos se expressam como os principais limites dos atuais currículos para formar profissionais para atuar na Saúde Mental em todo o país. Quando os currículos não negam a Saúde Mental, simplesmente despotencializam seu campo reivindicatório e político, desconsiderando temas relacionados aos movimentos de Reforma Psiquiátrica, Luta Antimanicomial e Estratégia de Atenção Psicossocial; ou seja, reduzem a área à psicopatologia tradicional, sob o crivo de procedimentos clínicos, psicoterápicos e medicalizadores da vida cotidiana, portanto, de manutenção e aperfeiçoamento das formas de tutela, infantilização e anulação do sujeito.

Tal quadro torna-se ainda mais preocupante quando justapomos tais questões ao perfil da formação pósgraduada dos entrevistados. Dos 29 entrevistados, contamos 24 profissionais com pós-graduação, sendo a maioria com especialização em saúde mental/atenção psicossocial $(\mathrm{n}=17)$, saúde pública $(\mathrm{n}=1)$, saúde da 
família $(\mathrm{n}=1)$, residência em saúde mental $(\mathrm{n}=1)$ e mestrado em saúde coletiva $(n=1)$. Os demais possuem especialização em psicologia clínica e atuam nos CAPS $(\mathrm{n}=3)$. Por fim, é importante notar que apesar de possuírem formação pós-graduada em saúde mental (e correlatos), na prática, isso não se materializa em aportes teórico-metodológicos e ferramentas técnicas-práticas que fundamentem as compreensões e as formas de atuar da maioria dos entrevistados em consonância aos ideários da Reforma Psiquiátrica, Luta Antimanicomial e Paradigma Psicossocial.

\section{Efeitos das "escolhas" teórico-metodológicas e dos modos de atuar dos psicólogos piauienses para Reforma Psiquiátrica}

Conhecida a maneira como os entrevistados manejam os saberes e práticas que definem seus modos de trabalho na Política de Saúde Mental na capital piauiense, ponderamos que, dependendo das "escolhas" teórico-metodológicas e prático-profissionais utilizadas neste campo, cada uma delas pode produzir determinados efeitos sobre as linhas de ação produtora de cuidado em saúde mental, como também sobre como estes profissionais se implicam com a realidade em que estão inseridos. Para melhor explorar tal argumento, apresentaremos os efeitos que é atuar em serviços que reproduzem modos de funcionamento estritamente disciplinar, considerando as formas de atuar dos entrevistados, fundamentalmente marcada pelo saber-fazer clássico da profissão, ainda hegemônico, independente da época de formação e o lugar de atuação:

- Cada profissional encontra-se entrincheirado em sua disciplina ou campo de saber que lhe é próprio, portanto, restrito à atividade que desenvolve;

- Os serviços reproduzem a noção de indivíduo doente, com foco no sintoma e pouca preocupação com relação à história, a cultura e os projetos de futuro dos pacientes;

- Quanto aos psicólogos, estes buscam na história do paciente e da doença, os aspectos intrapsíquicos, afetivos e comportamentais, portanto, os elementos que referem sobre a especificidade do seu saber-fazer neste campo;

- Baixa capacidade dos psicólogos elegerem ou investirem novas práticas, ou introduzirem algumas variações no seu repertório técnicoprofissional, para não cair na cronificação das práticas e das relações no serviço;

- Os CAPS não conseguem construir respostas em situações de crise psiquiátrica: ou o paciente segue para internação, como na maioria dos casos, ou permanece no serviço como exclusivo da esfera médica. Nossos entrevistados referiram não se envolverem nesse tipo de situação;

- Os profissionais participam muito pouco de reuniões de equipe para discutir questões técnicas e gerenciais dos serviços: técnicas no sentido do acompanhamento/evolução dos casos, construir/ revisar projetos terapêuticos e supervisionar os profissionais de apoio (artesãos, educadores físicos, educadores sociais, arte-terapeutas) para que suas ações possam contribuir para o processo terapêutico dos pacientes; gerenciais por tratar da organização dos processos de trabalho e do funcionamento da Política de Saúde Mental local. Quando muito, as reuniões são apenas para definir questões administrativas dos serviços;

- Nos ambulatórios e centros/unidades de saúde, bem como nos hospitais psiquiátricos, não se realiza qualquer ação interdisciplinar e interprofissional para a produção do cuidado dos pacientes, muito menos ações de articulação da rede de serviços e/ou junto à comunidade.

Como "efeito-dominó" de tais práticas, observamos os seguintes desdobramentos das linhas de atenção e cuidado operacionalizados pelos serviços investigados:

- Nos CAPS, os pacientes acabam "aprisionados" nas "grades" das inúmeras atividades e rotinas do serviço: consultas com psiquiatra e psicólogo; atendimento com assistente social, se necessário; administração de medicamentos pela enfermagem; atividades grupais com finalidade educativa e terapêutica, por segmento profissional; oficinas com terapeuta ocupacional e artesãos/educadores;

- Nos ambulatórios e centros/unidades de saúde, os pacientes têm acesso apenas a consultas profissionais individuais;

- Em um dos hospitais psiquiátricos, os pacientes ficam literalmente aprisionados nas enfermarias, sendo periodicamente avaliados por psiquiatras e psicólogos quanto ao seu quadro psicopatológico, até ocorrer, somente por meio da ação medicamentosa, a remissão dos sintomas ou compensação do quadro clínico.

- Quanto às oficinas terapêuticas dos CAPS, seu lema, conforme nos reportou alguns dos entrevistados, era: "- quase nunca deixar o usuário ocioso no serviço". Assim, tais atividades têm um caráter somente ocupacional, com a repetição de ações manuais em vez de terapêuticas, que operem: a produção e expressão de desejo, novos sentidos, sensibilidades, habilidades, enfim, produção de vida, projetos de futuro e de diferença para o usuário;

- Não há qualquer abertura ou disposição dos técnicos dos CAPS para realizarem assembleias ou reuniões com a participação de usuários e equipe técnica, para discutir os problemas rotineiros, sugestões, reclamações e dificuldades do serviço, contribuindo para a participação e autonomia do usuário;

- Uma vez inserido nos CAPS, o paciente tem como profissional de referência aquele que realizou sua triagem, independente se ficou estabelecido ou não o vínculo terapêutico; em seguida, participa de todas as atividades do serviço sem qualquer 
avaliação ou monitoramento se a mesma contribui ou não para o seu processo terapêutico e de reinserção social;

- É comum o uso de instrumentos de testagem psicológica (psicometria) na triagem para o ingresso nos CAPS. Tal recurso objetiva o enquadramento de "hipóteses" diagnósticas mais precisas, inclusive legitimando o fazer dos psicólogos entre os psiquiatras;

- A atenção básica e os CAPS quase não desenvolvem ações voltadas para a comunidade onde os usuários vivem, bem como para sua família, de modo a integrá-los em ações de continuidade das linhas de cuidado trabalhadas pelos serviços;

- Percebe-se o pouco envolvimento dos entrevistados da atenção básica com os casos dos chamados "mentais";

- Não há qualquer articulação entre os serviços (atenção básica, CAPS e hospital psiquiátrico) para a consecução de linhas de cuidado, salvaguardo nos casos de crise para internação, em que o foco da ação é suprimir a crise a qualquer custo.

Meio às escolhas e os efeitos que marcam a presença da nossa categoria na Política de Saúde Mental, argumentamos que os psicólogos piauienses se mostram bem mais vinculados ou comprometidos com a natureza da sua profissão, em termos dos saberes e práticas que os legitimam socialmente enquanto profissionais psi (mandato social da profissão) do que, efetivamente, com as novas práticas e com a cultura antimanicomial organizada sob o paradigma da desinstitucionalização e da atenção psicossocial. Nesse aspecto, observamos poucas ações dos profissionais entrevistados como um agente mobilizador de ações que contribuam com o processo de cuidado, reinserção social e produção de cidadania de usuários e familiares no cotidiano dos serviços. É nítida a dificuldade dos entrevistados em empreenderem, pelo menos no campo técnico, ações capazes de estabelecer relações menos produtora de subjetividades anuladas e empobrecidas. Por conseguinte, precisamos avançar sobre o modo como atuamos nos serviços, com a eleição de norteadores teórico-técnicos que promovam e fortaleçam a potência que os usuários têm de: a) estabelecer relações e projetos futuros; b) aumentar sua capacidade de escolha, participação e gerenciamento de sua vida; como também, c) percorrer caminhos para a conquista de autonomia, cidadania e poder de contratualidade, interferindo, inclusive no funcionamento dos serviços, na Política de Saúde Mental e na sociedade em geral.

\section{Considerações Finais}

Apesar do amplo discurso em torno da luta antimanicomial e em defesa do processo de reforma psiquiátrica que permeia a categoria dos psicólogos, observa-se certo descompasso entre o campo de ação política da nossa profissão, operada no plano nacional, com o campo de ação prático-profissional, operada no plano local. Nesse sentido, chama-nos atenção o quanto a formação graduada dos entrevistados, apesar de recente, não forneceu suporte para atuação na Política de Saúde Mental; e como isso ocorre independente do período, local e instituição em que estes profissionais foram formados. Sobre a formação pós-graduada, observouse que, mesmo tendo cursado especializações na área, os entrevistados investiram (ou incorporaram) muito pouco em termos de saberes e/ou práticas pertinentes ao paradigma psicossocial no campo de ação técnicoprofissional cotidiano dos serviços. Como consequência, apesar do discurso de engajamento a favor da luta antimanicomial, na prática, os psicólogos investigados se sentem despreparados, receosos e, algumas vezes, temerosos para lidarem com pacientes psiquiátricos e as demandas dos serviços. Além disso, relataram preferir pacientes com menor comprometimento afetivo e social, portanto, de fácil adesão ao modus operandi (enquadre) da sua profissão, pois assim se requer pouca alteração nas linhas de ação daquilo que representa o repertório técnicoprofissional clássico do fazer profissional do psicólogo.

O desdobramento disso para os profissionais não poderia ser outro, em resumo: a) a preferência por atuações individuais; b) busca de nexos causais para a compreensão do quadro clínico e psicossocial baseado somente nas definições de normal/patológico, que coloca a psiquiátrica tradicional; c) busca de nexos causais entre as queixas clínicas e os procedimentos mais efetivos para a remissão dos sintomas e normalização do paciente; c) realização de ações isoladas, justificadas pelo respeito da ética profissional, em termos de garantia do sigilo referente aos conteúdos do paciente em situações de atendimento - por isto a esquiva da atuação em equipe; d) trabalho técnico dissociado das ações de gestão, seja no próprio serviço, seja em termos da organização municipal e estadual da execução da Política de Saúde Mental.

Semelhante ao afirmado sobre a formação graduada e pós-graduada, os saberes e práticas investigados, ao longo deste estudo, também se revelam como basicamente os mesmos independente do tipo de instituição, local e época em que o entrevistado se graduou ou pós-graduou; ou do local de atuação, da população atendida, das necessidades e demandas requeridas, e do nível de assistência o qual o profissional está vinculado presta atendimento (atenção básica, setor ambulatorial, CAPS e hospital psiquiátrico). Assim, compreendemos que apesar de algumas mudanças no perfil da formação dos psicólogos nos últimos anos, não tivemos alterações significativas, pelo menos no contexto piauiense, com relação ao forte comprometimento afetivo da profissão com aquilo que a vincula, classicamente, à natureza do seu trabalho: atendimento clínico individual para o ajustamento de condutas (GONDIM; MAGALHÃES; BASTOS, 2010). E mesmo com o fortalecimento da produção acadêmica e profissional mais crítica sobre a profissão nas duas últimas décadas, ainda sim percebemos que a Psicologia, além de ter se fortalecido e se projetado como um saber legítimo e "cientificamente" adequado, tem se conformado como um campo de práticas essencial à sociedade, portanto, 
"intrinsecamente bom, competente, produtor de verdade e libertário, em qualquer situação que seja utilizado" (FIGUEIRA, 1985, p. 10-11).

Desse modo, entendemos que não conseguimos ampliar o repertório teórico-prático que performatizou, ao longo de décadas, o modo de sermos psicólogos que tanto nos identifica como profissionais bastante comprometidos: a) com o manejo fiel e preciso do arsenal teórico-técnico próprio do campo psi, que tanto qualifica nossa ciência como um saber autônomo e que se basta na tarefa de alcançar a verdade do/no indivíduo (DIMENSTEIN, 2000); b) com a manutenção de determinadas características pessoal-profissional definidora do modo de sermos profissionais sempre de atitude acolhedora, discreta, com capacidade analítica, compreensiva e respeitosa, que não interfere sobre a capacidade/desejo/interesse do paciente na direção que este quer dá ao trabalho, e garante a privacidade e o sigilo profissional (GONDIM; MAGALHÃES; BASTOS, 2010); e c) com a manutenção de settings pré definidos de trabalho, que propicie condições ideais para operarmos nosso instrumental teórico-técnico e explorarmos as características pessoal-profissionais necessárias para conduzimos com competência àquilo que representa a especificidade e a natureza daquilo que configura o nosso trabalho.

Por este aspecto, temos esbarrado em algo fundamental para avançarmos com atuações mais qualificadas no campo da Saúde Mental piauiense. Ou seja, o modo como concebemos historicamente nossa profissão e o apego ao que define tradicionalmente a natureza do trabalho do psicólogo, têm limitado nosso saber-fazer de maneira a colocá-lo pouco consoante com a perspectiva da atenção psicossocial, consequentemente, não dá sustentação ao processo de reforma psiquiátrica em curso no país.

Questões semelhantes a essa ainda são preocupações atuais no âmbito da formação do psicólogo, especialmente no campo das políticas públicas. As críticas referemse às imprecisões da nossa profissão quanto aos modos de conhecer e intervir associados às práticas que deem sustentação ao papel universal/redistributivo das políticas públicas, e com a garantia real de respostas para as necessidades da população com demandas sociais e em saúde mental (SPINK et al, 2007; BOARINI; BORGES, 2009; YAMAMOTO; OLIVEIRA, 2010). As críticas reportam ainda para as práticas, as representações e as compreensões sobre o processo de desinstitucionalização (SALES; DIMENSTEIN, 2009a, 2009b; FERREIRA NETO, 2008, 2010), além de referirem sobre a questão dos currículos e de qualificação profissional (GUARESCHI; REIS, 2010). Tal cenário torna o contexto piauiense não apenas um mero caso isolado. Ele faz parte de uma problemática em âmbito nacional que precisa de uma recondução urgente com políticas de formação que possam ampliar o repertório teórico-prático e o poder de ação profissional dos psicólogos no cotidiano dos serviços. Talvez assim, quem sabe, possamos requalificar o compromisso e o vínculo afetivo-profissional que tanto marca a identidade da nossa categoria, ampliando os elementos constituintes da natureza do nosso trabalho, especialmente no âmbito da Política de Saúde Mental.

\section{Referências}

AMARANTE, P. O homem e a serpente: outras histórias para a loucura e a psiquiatria. Rio de Janeiro: Fiocruz, 1996.

BASTOS, A. V. B.; ACHCAR, R. Dinâmica profissional e formação do psicólogo: uma perspectiva de integração. In: CFP. Psicólogo brasileiro: práticas emergentes e desafios para a formação. São Paulo: Casa do Psicólogo, 1994. p. 245-272.

BASTOS, A. V. B.; GONDIM, S. M. G.; RODRIGUES, A. C. A. Uma categoria profissional em expansão: quantos somos e onde estamos? In: BASTOS, A. V. B.; GONDIM, S. M. G. (Org.). O trabalho do psicólogo no Brasil. Porto Alegre: Artmed, 2010. p. 32-44.

BOARINI, M. L.; BORGES, R. F. O psicólogo na atenção básica à saúde. Psicologia Ciência e Profissão, Brasília, v. 29, n. 3, p. 602-613, set. 2009.

BRASIL. Ministério da Saúde. Saúde mental em dados 8 . Informativo eletrônico de dados sobre a Politica Nacional de Saúde Mental, Brasília, ano 6, n. 8, jan. 2011. Disponível em: <http://bvsms.saude.gov.br/bvs/periodicos/saude_mental dados_v8.pdf> Acesso em: 20 maio 2011.

CAMPOS, F. C. B.; GUARIDO, E. L. O psicólogo no SUS: suas práticas e as necessidades de quem o procura. In: SPINK, M. J. P. (Org.). A psicologia em diálogo com o SUS: prática profissional e produção acadêmica. São Paulo: Casa do Psicólogo, 2007. p. 81-104.

CAMPOS, G. W. S. Saúde paidéia. São Paulo: Hucitec, 2003.

DIMENSTEIN, M. O psicólogo nas unidades básicas de saúde: desafios para a formação e atuação profissionais. Estudos de Psicologia, Natal, v. 3, n. 1, p. 53-81, jan./jul. 1998.

DIMENSTEIN, M. A cultura profissional do psicólogo e o ideário individualista: implicações para a prática no campo da assistência pública à saúde. Estudos de Psicologia, Natal, v. 5, n. 1, p. 95-122, jan. 2000.

DIMENSTEIN, M. O psicólogo e o compromisso social no contexto da saúde coletiva. Psicologia em Estudo, Maringá, v. 6, n. 2, p. 57-63, jul. 2001. Disponível em: <http://www.scielo. br/pdf/pe/v6n2/v6n2a08.pdf>. Acesso em: 20 maio 2011.

DIMENSTEIN, M. (Org.). Produção do conhecimento, agenciamentos e implicação no fazer pesquisa em Psicologia. Natal: EDUFRN, 2009.

FERREIRA NETO, J. L. Intervenção psicossocial em saúde e formação do psicólogo. Psicologia e Sociedade, Porto Alegre, v. 20, n. 1, p. 62-69, jan./abr. 2008. Disponível em: <http:/ www.scielo.br/pdf/psoc/v20n1/a07v20n1.pdf>. Acesso em: 20 maio 2011 .

FERREIRA NETO, J. L. A atuação do psicólogo no SUS: análise de alguns impasses. Psicologia Ciência e Profissão, Brasília, v. 30, n. 2, p. 390-403, jun. 2010.

FIGUEIRA, S. Psicologismo, psicanalismo e ciências sociais na "cultura psicanalística". In: FIGUEIRA, S. A. Cultura da psicanálise. São Paulo: Brasiliense, 1985. p. 169-177.

GONDIM, S. M. G.; MAGAlHÃES, M. O.; BASTOS, A. V. B. Escolha da profissão: as explicações construídas pelos psicólogos brasileiros. In: BASTOS, A. V. B.; GONDIM, S. 
M. G. (Org.). O trabalho do psicólogo no Brasil. Porto Alegre: Artmed, 2010. p. 66-84.

GUARESCHI, N. M. F.; REIS, C. Encontros e desencontros entre psicologia e política: formando, deformando, transformando profissionais de saúde. Psicologia Ciência e Profissão, Brasília, v. 30, n. 4, p. 854-867, out./dez. 2010. Disponível em: <http:/ pepsic.bvsalud.org/pdf/pcp/v30n4/v30n4a14.pdf>. Acesso em: 20 maio 2011.

MACEDO, J. P.; DIMENSTEIN, M. Formação profissional no campo da saúde mental: a psicologia piauiense em análise. Interface - Comunicação, Saúde e Educação, Botucatu, v. 15, n. 39, p. 1145-1158, ago. 2011. Disponível em: <http://www.scielo. br/scielo.php?pid=S1414-32832011000400014\&script=sci abstract\&tlng=pt>. Acesso em: 22 jan. 2012.

MACÊDO, K. B.; HELOANI, R.; CASSIOLATO, R. O psicólogo como trabalhador assalariado: setores de inserção, locais, atividades e condições de trabalho. In: BASTOS, A. V. B.; GONDIM, S. M. G. (Org.). O trabalho do psicólogo no Brasil. Porto Alegre: Artmed, 2010. p. 131-150.

MINAYO, M. C. S. O desafio do conhecimento: pesquisa qualitativa em saúde. 7. ed. São Paulo: Hucitec. 2000.

OLIVEIRA, W. F. Algumas reflexões sobre as bases conceituais da saúde mental e sobre a formação do profissional de saúde mental no contexto da promoção da saúde. Saúde em Debate, Rio de Janeiro, v. 32, n. 78/79/80, p. 38-48, jan./dez. 2008.

PASSOS, E.; BARROS, R. B. A construção do plano da clínica e o conceito de transdisciplinaridade. Psicologia: Teoria e Pesquisa, Brasília, v. 16, n. 1, p. 71-79, jan./abr. 2000. Disponível em: <http://www.scielo.br/pdf/ptp/v16n1/4390. pdf $>$. Acesso em: 20 maio 2011.

RIBEIRO, S. L.; LUZIO, C. A. As diretrizes curriculares e a formação do psicólogo para a saúde mental. Psicologia em Revista, Belo Horizonte, v. 14, n. 2, p. 203-220, dez. 2008. Disponível em: <http://periodicos.pucminas.br/index.php/ psicologiaemrevista/article/viewArticle/350>. Acesso em: 20 maio 2011.

ROSA, L. C. S. O nordeste na reforma psiquiátrica. Teresina: EDUFPI, 2006.

SALES, A. L.; DIMENSTEIN, M. Psicologia e modos de trabalho no contexto da Reforma Psiquiátrica. Psicologia Ciência e Profissão, Brasília, v. 29, n. 4, p. 812-827, out./dez. 2009a. Disponível em: <http://pepsic.bvsalud.org/pdf/pcp/ v29n4/v29n4a12.pdf>. Acesso em: 20 maio 2011.

SALES, A. L.; DIMENSTEIN, M. Psicólogos no processo de reforma psiquiátrica: práticas em desconstrução? Psicologia em Estudo, Maringá, v. 14, n. 2, p. 277-285, abr.jul. 2009 b. Disponível em: <http://www.scielo.br/pdf/pe/v14n2/v14n2a07. pdf $>$. Acesso em: 20 maio 2011.

SPINK, M. J. et al. A inserção de psicólogos em serviços de saúde vinculados ao SUS: subsídios para entender os dilemas da prática e os desafios da formação profissional. In: SPINK, M. J. P. (Org.). A psicologia em diálogo com o SUS: prática profissional e produção acadêmica. São Paulo: Casa do Psicólogo, 2007. p. 53-79.

VASCONCELOS, E. M. (Org.). Desafios políticos no campo da saúde mental na atual conjuntura: uma contribuição ao debate da IV Conferência Nacional. In: . Desafios políticos da reforma psiquiátrica brasileira. São Paulo: Hucitec, 2010. p. 17-74.

Fractal, Rev. Psicol., v. 28 - n. 1, p. 37-45, 2016
YAMAMOTO, O. H., OLIVEIRA, I. F. Política social e psicologia: uma trajetória de 25 anos. Psicologia: Teoria e Pesquisa, Brasília, v. 26, n. 26, p. 9-24, no. spe. 2010. Disponível em: <http://www.scielo.br/pdf/ptp/v26nspe/a02v26ns.pdfs. Acesso em: 20 maio 2011.

YASUI, S.; COSTA-ROSA, A. A estratégia atenção psicossocial: desafio na prática dos novos dispositivos de saúde mental. Saúde em Debate, Rio de Janeiro, v. 32, n. 78/79/80, p. 27-37, jan./dez. 2008.

Recebido em: 13 de novembro de 2012 Aceito em: 22 de abril de 2015 